\title{
Unconditional Support for Trump's Resistance Prior to Election Day in Public Opinion
}

Brendan Hartnett, Tufts University Alexandra Haver, Tufts University

\begin{abstract}
Using survey data collected less than two weeks prior to the 2020 Presidential Election, we investigate why likely Trump voters would support Trump resisting the results of the election if he lost. We first do this using an experiment with randomized hypothetical popular vote margins to test if support for resistance is contingent upon the results of the election itself. We also directly ask respondents who said they would support resistance to explain their reasoning in an openended response. In doing so, we gain insight into one of the most turbulent elections in American history and examine how support for resistance existed prior to the election itself due to both misinformation about voter fraud and hyper-partisanship which made Trump voters view the electoral process itself as illegitimate.
\end{abstract}




\section{Introduction}

Leading up to the 2020 Presidential Election, it was unclear, for the first time since the Election of 1800, whether the incumbent president would accept electoral defeat. In the third debate of the 2016 Presidential Election, President Trump refused to commit to accepting the election results if he lost (Gellman 2020). Soon after, he told supporters that he would "totally accept the results [of the 2016 Presidential Election] ..." but followed the statement with "if I win!" (Diamond 2016). As Trump won the Electoral College, this threat was never tested. However, in the third presidential debate of the 2020 Presidential Election, Trump again refused to commit to accepting the election results, stating that the only way he could lose would be due to fraud from mail-in-ballots used amid the COVID-19 pandemic (Gellman 2020). This threat was then substantiated when Trump lost both the popular vote and the Electoral College but refused to concede.

With the rampant spread of what has come to be known as "the Big Lie" — which argued that the election was riddled with fraud, particularly due to the use of mail-in-ballots-it appeared that Trump was not alone in rejecting the legitimacy of the democratic process. A Reuters/Ipsos poll fielded in October 2020 directly asked voters whether they would accept the results of the election if their preferred candidate lost. Although minimal context was provided, and the question did not ask what the candidates themselves should do, the poll found that $41 \%$ of likely Trump voters would not accept a Biden victory, and 16\% of all likely Trump voters "would engage in street protests or even violence" (Kahn 2020).

Amid the uncertainty preceding the election, we conducted a survey experiment in October 2020 to examine the extent to which Trump's voters would support him if he lost the election but refused to concede. The results indicate that the insurrection on January 6, 2021, was 
not a surprise, but a manifestation of an illiberal and contentious culture surrounding the 2020 Presidential Election fostered by Trump's divisive rhetoric and misinformation campaign.

We explored the following question: Would a higher popular vote margin of victory for Biden increase the acceptance of his Electoral College victory among Trump voters? If higher popular vote margins were met with greater support for Trump accepting the election and conceding defeat, this could indicate that Trump supporters' acceptance of the legitimacy of the 2020 Presidential Election was contingent upon the election results themselves. However, if support for resistance was unrelated to the popular vote margins, this could indicate that the legitimacy of the election and its victor were determined before the vote itself. Further, to understand the rationale guiding those who would support Trump in resisting the results of the 2020 Presidential Election, we asked respondents to explain their motivations in their own words.

This study proposes an explanation for one of the most turbulent elections in American history. By probing support for Trump's resistance prior to the election, we provide insight into how a fundamental tradition of American democracy was nearly disposed of. Additionally, we gain an understanding of how messaging from elites, regarding both election fraud and partisan affairs, affected Trump voters' respect for the legitimacy of the 2020 Presidential Election. The study highlights how the rhetoric and actions of elites culminated in a disregard for the democratic electoral process among Trump voters.

\section{Understanding Resistance}

\subsection{The Big Lie and the Effects of Misinformation}


The spread and severity of misinformation have grown dramatically in the United States, bolstered by Trump's labeling of traditional media outlets as "fake news" (Oehmichen et al. 2019). Baseless allegations of voter fraud in the 2016 Presidential Election were levied by both right-wing pundits and Trump himself, who claimed that he won the popular vote "if you deduct the millions of people who voted illegally.” (Wootson 2016). After assuming office, Trump created the Presidential Advisory Commission on Election Integrity, tasked with, among other things, investigating voter fraud (Nelson 2017). Trump's claims about voter fraud in the 2016 election established the framework for skepticism toward the validity of the 2020 Presidential Election (Oehmichen et al. 2019).

Misinformation in the 2020 presidential campaign was in full force, with Trump telling his followers that the only way he could lose would be through voter fraud (Badger 2020a). These lies espoused by Trump and right-wing pundits culminated in "the Big Lie," which Trump voters bought into, and is ultimately credited with inspiring the Capitol insurrection (Vachudova 2021).

Misinformation spread online is tactically catered to the political preferences of its viewers, driving polarization over conflict about what is the truth (Enders and Smallpage 2019). This reflects a tenet of misinformation: it is commonly accepted by those whose pre-existing beliefs, assumptions, and worldviews conform to the message (Swire et al. 2017). The supply of misinformation is, thus, received by voters who interpret new information through the lens of motivated reasoning. In doing this, individuals accept new information in ways that they find desirable, and reject evidence that contradicts their world views. This makes partisans especially susceptible to believing misinformation that supports their political preferences, substantially impacting their factual beliefs. 
Presented with the same information, partisans interpret that information differently to support their own beliefs (Enders and Smallpage 2019). When interpreting information such as the winner of an election, identity-protective cognition is employed, representing a way to avoid “dissonance and estrangement from valued groups," such as political parties, that leads "individuals [to] subconsciously resist factual information that threatens their defining values" (Kahan, Jenkins-Smith, and Braman 2011, 149; Kahan et al. 2012, 733).

Identity-protective cognition made Trump voters more susceptible to Trump's unfounded claims of voter fraud leading up to — and well after- the 2020 Presidential Election. Due to the prominence of misinformation catered to the political right, surveys conducted prior to Election Day found that Republicans were more likely than Democrats to have concern abouts the integrity of the 2020 Presidential Election (Persily and Stewart 2021). Furthermore, in a study on the effects of misinformation spread on social media, Berlinski et al. (2021) concluded that exposure to any misinformation significantly reduced Republicans' and Trump voters' confidence in U.S. electoral integrity — no matter how much they were exposed to it.

We thus believed that most respondents who would support Trump resisting the results of the election would justify their position on the grounds of perceived fraud in the election. Specifically, we predicted most respondents would indicate that Trump would lose due to fraud involving the unprecedented use of mail-in voting due to the COVID-19 pandemic, which Trump, prior to election day, claimed would be the only way he could lose to Biden, warranting hid resistance in their eyes. These respondents would thus be supportive of Trump resisting the results of the election due to misinformation about the integrity of the election spread from elites to the public.

\subsection{Partisan Motivations for Undermining Election Results}


In contrast to those who support resistance due to concerns about the legitimacy of the election, some respondents may support Trump's efforts to resist free and fair election results due to partisan cheerleading, by purposely basing their responses on information they know to be inaccurate (e.g., voter fraud and malpractice) merely out of a desire to support their party (Bullock et al. 2020). This form of expressive responding persists even when the information presented offers a clear truth. For example, when respondents were presented with photographs of Obama's and Trump's respective inauguration crowds, "the most politically engaged Trump supporters," falsely claimed that Trump's inauguration photograph depicted a larger crow; in doing so, they provided "expressive responses to a straightforward question related to controversy" in which the factual answer was clear (Schaffner and Luks 2018, 142). These findings suggest that some Trump voters in our survey could state that Trump should resist disappointing results, not because they necessarily think the results are fraudulent, but rather to signal their political support for him.

Partisan cheerleading, however, presents a novel issue in our survey. Fundamentally, Trump supporters' engagement in partisan cheerleading in our study is antithetical to the principles of liberal democracy, as those respondents express a willingness to undermine the democratic electoral process for partisan ends. Indeed, partisan support for undermining free and fair election results is a hallmark of competitive authoritarianism (see, for example, Levitsky and Way 2010; Levitsky and Ziblatt 2018). As such, it must be examined why partisans would support efforts to undermine the legitimacy of elections by refusing to accept credible election results.

We suspected that some Trump supporters may support Trump's efforts to resist defeat simply because he is their preferred candidate, or because they are opposed to Democratic rule. 
The latter is an extreme case of negative partisanship and has proven to lead to public support for illiberal actions - particularly in comparative studies of executive aggrandizement (Cleary and Öztürk 2020). In their analysis of American voters serving as a check on undemocratic candidates, Graham and Svolik (2020) find that when two candidates are ideologically opposed, voters are less likely to punish the candidate who aligns with their policy interests when they exhibit undemocratic behavior. Their findings can clearly be applied to the 2020 Presidential Election, given that both the candidates and voters were more polarized in 2020 than in any election in recent history (Jacobson 2021). Thus, applying Graham and Svolik's (2020) methods to our survey experiment, we would expect that some voters would, rather than simply tolerate illiberal candidates, actively endorse their preferred candidate's undemocratic actions rather than tolerate opposition rule.

Particularly, we assume that those who identify their partisan affiliation as "strong Republicans" would be significantly more likely to support Trump's efforts at resisting the outcome than Independents or moderate Republicans voting for Trump, given their policy interests are likely more aligned with Trump than those in the latter group; therefore, the opportunity cost of not having Trump in office is higher for these voters than it is for more centrist voters. In their survey experiment, Graham and Svolik (2020) find that moderate and centrist voters serve as a pro-democratic check on illiberal politicians, warranting our expectation.

Those who support Trump resisting the results of the election for partisan reasons will likely provide partisan explanations to our open-ended question. We expect that they will cite either that Trump is their preferred candidate and thus they want him to be in power no matter 
what, or that they are highly opposed to Democratic rule and are willing to undermine the electoral process to ensure that such an outcome does not occur.

\section{Methods and Data}

We explored our research questions in a survey fielded online to 1,208 American adult respondents recruited via Lucid between October 24 and October 25, 2020. Post-stratification weights were applied to make the survey nationally representative of American adults by gender, age, region, education, race, and 2016 Presidential vote, with targets defined by the most recent 5-year American Community Survey.

Respondents were asked if they intended to vote in the 2020 general election. Those who said they planned to vote, would probably vote, had already voted (by either mail or early voting), or were undecided were then asked for their presidential vote choice. Those who had already voted for Trump, planned to vote for Trump, or leaned towards voting for Trump were categorized as Trump voters $(n=510)$.

After the preface, "The following question will ask about a hypothetical outcome of the 2020 presidential election. Please choose the answer that best reflects your preferences," Trump voters were presented with a statement that read: "Biden wins the popular vote by _ percentage points and wins the Electoral College." Each respondent received a randomized popular vote margin, which ranged between 1 and 15 points. Respondents were then asked: "The Trump campaign should..."

a. "Resist the results of the election through measures such as discrediting the results as invalid, declaring a state of emergency, and/or taking any means possible to remain in office,"

b. "Concede defeat and commit to a peaceful transfer of power." 
We chose to randomly assign the hypothetical popular vote margin to an integer between 1-15 percentage points for Biden based on polling aggregates from FiveThirtyEight, The Economist, and Real Clear Politics in mid-October. At the time of our study, there was less than a $6 \%$ chance of Trump winning the popular vote, warranting our exclusion of such a scenario (Silver 2020). The ways by which Trump could resist the results of an electoral defeat that we listed corresponded to common tactics employed by autocratic leaders within liberal democracies. Gellman (2020) applied these possible tactics to the U.S. Presidential Election, arguing in September 2020 that Trump could refuse to accept defeat by filing lawsuits to challenge the results, demanding states send conflicting electors to the Electoral College, or declaring a national emergency to inhibit the peaceful transfer of power.

Using this data, we conducted two logit regression analyses using generalized linear models. The first model simply tested if the randomly assigned popular vote margin treatment affected likely Trump voters' support for his resistance. The second model analyzed how the demographics of respondents were associated with their support for Trump's resistance, using variables for a respondent's age range, level of education, household income, self-reported party identification, and gender. It also tested the extent to which one's interest in the news and acknowledgement of racism (see Schaffner 2020) impacted support for resistance.

To respondents who said Trump should resist the election results, we asked a follow-up open-ended question: "Why should the Trump campaign resist the results of the election? Please be as specific as possible." We categorized these open-ended responses according to the rationale provided to support resistance and included those that provided more than one reason in multiple categories $(n=183)$. Themes observed in less than 10 responses were coded as "Other." 
Respondents who provided bogus responses or did not provide any answer $(n=23)$ were removed from the analysis.

These response categories were then categorized according to the theme motivating their support for resistance: partisanship/negative partisanship, concerns about election integrity, and all other responses. All responses fell in one of the three themes, with some responses included in more than one.

\section{Findings}

\subsection{Should Trump Resist?}

Figure 1 shows Biden's randomized hypothetical popular vote margin of victory against the percentage of Trump voters who responded that Trump should resist the election results if Biden won the Electoral College. About $45 \%$ opt for Trump to resist when Biden receives a margin of victory between 1-12 points. While support for resistance declines when respondents were given a scenario in which Biden wins the election by $13-15$ points, in total $40 \%$ of respondents support Trump resisting the results of the election. Even when respondents were provided a hypothetical scenario in which Biden's large margin of victory would make voter fraud concerns especially irrelevant, there was still widespread support for Trump resisting the outcome.

\section{[FIGURE 1 ABOUT HERE]}

These findings are consistent with other polls conducted prior to the election which probed how Trump voters would respond to a Biden Electoral College victory. Of the scenarios we presented, the most reflective of reality was when Biden won the popular vote by $4 \%$, given that he actually won by $3.9 \%$. Among those presented with this then-hypothetical, $44 \%$ responded that they would support Trump resisting the election results. 


\section{[TABLE 1 ABOUT HERE]}

Despite a slight downward trend in our figure, we failed to find a statistically significant relationship between the popular vote margin and support for Trump resting the election results $(p=.26)$. We also failed to find a significant relationship between education, household income and gender and support for resistance. Respondents over the age of 65 , however, were significantly less likely to support resistance than younger respondents. One's self-reported partisan identification also proved to have insignificant effects on support for resistance. To an extent, this goes against the theory provided by Graham and Svolnik (2020), as the application of their model would expect that more centrist voters would not support undemocratic actions to the same extent as hyper-partisans. However, this difference may be the result of our model using partisanship as a measure of alignment with Trump's policies, while their model used a linear continuum to measure one's policy alignments with a candidate. Furthermore, measurement of partisanship may not be a sufficient proxy for analyzing alignment with Trump's policies, particularly as independents and "leaners" are found to usually be actual partisans in their policy preferences (Petrocik 2009). No significant relationship was discovered between respondents' interest in news and current events, nor their acknowledgement of racism, on supporting Trump's resistance.

\subsection{Why Should Trump Resist?}

Table 2 shows the categories of responses to the open-ended question asking respondents' rationales for supporting Trump resisting the election results. The most common response was that Trump should resist the results because he was the respondent's preferred candidatelabeled "Support Trump." Examples of such responses include "[I] am saying this because I am for trump 2020" and "BECAUSE HE HAS DONE MORE FOR THIS COUTRY IN 4 YEARS 
THEN BIDEN HAS IN 47 YEARS.” These respondents justified their support for Trump working to overturn the results simply because he was their preferred candidate.

\section{[TABLE 2 ABOUT HERE]}

Similarly, opposition to the Democratic Party was common, with respondents perceiving Democrats to be ideological radicals. "Democrats are radicals" was coded as those who suggested a Biden presidency would undermine their perceptions of American traditions and values. These included general attacks on Democrats' policies and governance such as "Because the Democrats will ruin america" and "Democraps are destroying our nation," allegations of Democrats supporting socialism, such as "I don't want to live under Socialism and all that the Democrats stand for!" as well as perceptions of Democratic governance serving an ethno-cultural threat, such as "cause we dont want or need a woman of color as the vp!!!"

These two categories reflect hyper-partisanship for Trump and negative partisanship against the Democrats. To this group, the election itself appears irrelevant to the legitimacy of the presidency, with these respondents instead simply supporting resistance for partisan reasons. In total, this theme of supporting resistance because of hyper-partisanship or negative partisanship was present in $40 \%$ of responses.

Responses coded as "Election irregularities" were those that questioned the legitimacy of the election results, without explicitly mentioning mail-in-ballots or voter fraud, as well as those that alluded to the election being rigged, such as "there is no way biden is gonna win the election if the election [is] fair" and "the democrats are rigging the election." The category "Voter fraud/mail-in-ballots" included respondents who mentioned mail-in-ballots, including personal stories speculating they would be abused, such as "my experience, I've received 2 mail-in-ballots and individuals have never lived here," as well as statements arguing these ballots would be used 
to commit fraud favoring Democrats. Despite being touted before and after the election — and being the basis for Trump's challenge to the state election results - election irregularities, voter fraud, and issues with mail-in-ballots were cited by only $37 \%$ of respondents who would support Trump in resisting the results of the election.

Responses coded as "Democrats are corrupt" included "the Democrat party is totally corrupt," and "I personally think there is a hidden agenda, I never thought that way until I saw the so called [first] impeachment process and saw how absolutely corrupt the Democratic party is." Those who levied ad hominem attacks against Biden and his capacity to govern, but did not reference his policy positions, were coded as "Biden is Incompetent." These included "Because in reality Biden isn't fit," and "because biden is an idiot and there is no way he can lead this country as president."

The variance in responses reflects conflicting rationales for supporting Trump's resistance. Those who stated Trump should resist because he is their preferred candidate or because they dislike the Democratic Party appear to be motivated by hyper-partisanship or negative partisanship. To these respondents, their support for Trump resisting the results of the election was not inspired by concerns of electoral malpractice; instead, they simply did not care for the election itself, and wanted Trump in power no matter what. In contrast, those who cited reasons concerning the legitimacy of the election were largely inspired by misinformationnotably, "the Big Lie" - which likely led them to believe that the election would be rigged and fraudulent. Despite expecting issues concerning the legitimacy of the election to be the most common reason cited by respondents, we fail to find that it was cited more than reasons guided by partisanship or negative partisanship $(p=.74)$. 
As a result, we cannot conclude that support for resisting the election results was primarily driven by misinformation about election fraud. Instead, a significant portion of respondents supported resistance for partisan reasons, indicating that the declining legitimacy of the electoral process was not caused by misinformation alone, but also a lack of tolerance for the opposition and hyper-partisanship.

\section{Discussion}

While the Trump administration allowed a transition to begin on November 23, 2020, Trump refused to concede until after the Capitol insurrection. Before his account was suspended, Twitter flagged over 200 tweets by the former-President for false or disputed information pertaining to the election (Spangler 2020). It is undeniable that both Trump's lies about voter fraud and disrespect for the democratic process led to the January 6th insurrection.

The public support we found for Trump resisting hypothetical election results grew after his loss became reality. According to a poll conducted between November 15 and 17, 2020, only $12 \%$ of Trump voters believed "Biden legitimately won the election," compared to $57 \%$ of all voters (The Economist/YouGov 2020). The Economist/YouGov (2020) also found that 79\% of Trump voters believed Trump should not concede, $75 \%$ of Trump voters believed "Trump should not start the transition process," and only $48 \%$ of Trump voters believed that a peaceful transfer of power was likely to take place. This increase in support for resistance was likely the result of both partisan cheerleading for those who knew that Biden won but would not admit it, and by misinformation, for respondents who legitimately believed that Trump won when accounting for perceived voter fraud (Badger 2020b).

Nevertheless, the high level of support for Trump resisting defeat, as he did in the months following the election, is staggering when viewed in the context of contemporary American 
electoral history. With $40 \%$ of Trump voters in our study stating Trump should resist the results of the election even in scenarios in which Biden won by a large popular vote victory, the precedent of peaceful transfers of power in American elections was shaken prior to the election itself. Further, the rationale behind these respondents' eagerness for Trump to resist electoral defeat reflects the erosion of democratic norms. As such, it appears that misinformation pertaining to voter fraud and the use of mail-in-ballots cannot explain away all support for Trump's resistance, and that partisanship and negative partisanship also prompted voters to disregard the democratic electoral process entirely to support their preferred candidate in his quest for office by any means possible.

Our findings confirm the troubling consequences of the 2020 Presidential Election. Trump's resistance to election results enjoyed support before the election even took place. This has, of course, persisted as Trump continues to espouse "the Big Lie." At a rally in Arizona in January 2022, Trump lambasted "I ran twice, I won twice... we did much better the second time... Get out and vote. Make sure it's not a rigged vote, please" (C-SPAN 2022). For Republican primary-hopefuls in the 2022 midterm elections, "the Big Lie" is proving successful, with 55\% of Republicans saying they were more likely to vote for a GOP Congressperson in 2022 who casts doubt on Biden's victory in a December 2021 survey (Hagan 2021). Ultimately, U.S. democracy faces a critical junction, with elites working to subvert it, cheered on by the masses since even before the 2020 Presidential Election.

\section{References}

Badger, Emily. 2020a. "Americans are Afraid. Not for Themselves, but for the Country." The New York Times, November 1. <www.nytimes.com/2020/11/01/upshot/electiondemocracy-fear-americans.html>. 
Badger, Emily. 2020b. "Most Republicans Say They Doubt the Election. How Many Really Mean It?" The New York Times, November 30.

$<$ https://www.nytimes.com/2020/11/30/upshot/republican-voters-election-doubts.html>.

Berlinski, Nicholas, Margaret Doyle, Andrew M. Guess, Gabrielle Levy, Benjamin Lyons, Jacob M. Montgomery, Brendan Nyhan and Jason Reifler. "The Effects of Unsubstantiated Claims of Voter Fraud on Confidence in Elections." The Journal of Experimental Political Science: 1-16. Doi: 10.1017/XPS.2021.18.

Bullock, John G., Alan S. Gerber, Seth J. Hill and Gregory A. Huber. 2015. "Partisan Bias in Factual Beliefs about Politics”, Quarterly Journal of Political Science 10 (4): 519-578. Doi: $10.1561 / 100.00014074$.

Cleary, Matthew R. and Aykut Öztürk. 2020. "When Does Backsliding Lead to Breakdown? Uncertainty and Opposition Strategies in Democracies at Risk." Perspectives on Politics: 1-17. doi: 10.1017/S1537592720003667.

C-SPAN. 2022. "Former President Trump Speaks at Arizona Republican Party Political Rally." C-SPAN, January 15. https://www.c-span.org/video/?517043-1/president-trump-speaksarizona-gop-political-rally\&event=517043\&playEvent\&auto.

Diamond, Jeremy. 2016. "Donald Trump: 'I will totally accept' election results 'if I win.'” CNN, October 20. <https://www.cnn.com/2016/10/20/politics/donald-trump-i-will-totallyaccept-election-results-if-i-win/index.html $>$.

The Economist/YouGov. 2020. "The Economist/YouGov Poll November 15 - 17, 2020 - 1500 U.S. Registered Voters.” YouGov. $<$ https://docs.cdn.yougov.com/02yn0jg6d7/econTabReport.pdf $>$.

Enders, Adam M. and Steven M. Smallpage. 2019. "Information Cues, Partisan-Motivated Reasoning, and the Manipulation of Conspiracy Beliefs." Political Communication 36 (1): 83-102. Doi: 10.1080/10584609.2018.1493006.

Graham, Matthew., and Milan W. Svolik. 2020. "Democracy in America? Partisanship, Polarization, and the Robustness of Support for Democracy in the United States." American Political Science Review 114 (2): 392-409. Doi: 10.1017/S0003055420000052.

Gellman, Barton. 2020. "The Election That Could Break America.” The Atlantic, November. $<$ https://www.theatlantic.com/magazine/archive/2020/11/what-if-trump-refusesconcede/616424/>.

Hagan, Lisa. 2021. "Poll: A Third of Americans Question Legitimacy of Biden Victory Nearly a Year Since Jan. 6." U.S. News and World Report, December 28. https://www.usnews.com/news/politics/articles/2021-12-28/poll-a-third-of-americansquestion-legitimacy-of-biden-victory-nearly-a-year-since-jan-6. 
Jacobson, Gary. 2021. "Driven to Extremes: Donald Trump's Extraordinary Impact on the 2020 Elections.” Presidential Studies Quarterly 51 (3): 492-521. Doi: 10.1111/psq.12724.

Kahan, Dan M., Ellen Peters, Maggie Wittlin, Paul Slovic, Lisa Larrimore Ouellette, Donald Berman, and Gregory Mandel. 2012. "The Polarizing Impact of Science Literacy and Numeracy on Perceived Climate Change Risks.” Nature Climate Change 2: 732-735. Doi: $10.1038 /$ nclimate1547.

Kahan, Dan M., Hank Jenkins-Smith, and Donald Braman. 2011. "Cultural Cognition of Scientific Consensus.” The Journal of Risk Research 14 (2): 147-174. Doi: 10.1080/13669877.2010.511246.

Kahn, Chris. 2020. "Four in Ten Supporters of Biden, Trump would not Accept Election Defeat: Reuters/Ipsos poll.” Reuters, October 25. < https://www.reuters.com/article/us-usaelection-poll/four-in-ten-supporters-of-biden-trump-would-not-accept-election-defeatreuters-ipsos-poll-idUSKBN27A0BB >.

Levitsky, Steven. and Lucan Way. 2010. Competitive Authoritarianism: Hybrid Regimes after the Cold War. Cambridge: Cambridge University Press.

Levitsky, Steven. and Daniel Ziblatt. 2018. How Democracies Die. New York: Crown Publishing Group.

Nelson, Louis. 2017. "Trump Signs Executive Order Creating Voter Fraud Commission.” Politico, May 11.<https://www.politico.com/story/2017/05/11/trump-voter-fraudcommission-238263>.

Oehmichen, Axel, Kevin Hua, Julio Lopez, Miguel Molina-Solana, Juan Gómez-Romero and Yike Guo. 2019. "Not All Lies Are Equal. A Study into the Engineering of Political Misinformation in the 2016 US Presidential Election." IEEE Access: 1-1. Doi: 10.1109/ACCESS.2019.2938389.

Persily, Nathan and Charles Stewart III. 2021. "The Miracle and Tragedy of the 2020 U.S. Election.” The Journal of Democracy 32 (2): 159-178. Doi: 10.1353/jod.2021.0026.

Petrocik, John Richard. 2009. "Measuring Party Support: Leaners are Not Independents." Electoral Studies 28 (4): 562-572. Doi: 10.1016/j.electstud.2009.05.022.

Schaffner, Brian F. 2022. "The Heightened Importance of Racism and Sexism in the 2018 US Midterm Elections.” British Journal of Political Science 52 (1): 492-500. doi: $10.1017 / \mathrm{S} 0007123420000319$.

Schaffner, Brian and Samantha Luks. 2018. "Misinformation or Expressive Responding? What an Inauguration Crowd Can Tell Us About the Source of Political Misinformation in Surveys." Public Opinion Quarterly 84 (1): 125-147. DOI: 10.1093/poq/nfx042. 
Silver, Nate. 2020. "2020 Election Forecast.” FiveThirtyEight. Accessed October 11, 2020. $<$ https://projects.fivethirtyeight.com/2020-election-forecast/>.

Spangler, Todd. 2020. “Twitter Has Flagged 200 of Trump's Posts as 'Disputed' or Misleading Since Election Day. Does it make a Difference?" Variety, November 27. $<$ https://variety.com/2020/digital/news/twitter-trump-200-disputed-misleading-claimselection-1234841137/>.

Swire, Birony, Adam J. Berzinksy, Stephan Lewandowsky, and Ullrich K. H. Ecker. 2017. "Processing Political Misinformation: Comprehending the Trump Phenomenon." The Royal Society of Open Science 4 (3): 1-21. Doi: 10.1098/rsos.160802.

Vachudova, Milada A. 2021. "Populism, Democracy, and Party System Change in Europe." Annual Review of Political Science 21 (1): 471-498. Doi: 10.1146/annurev-polisci041719-102711.

Wootson, Cleve, R. 2016. "Donald Trump: 'I Won the Popular Vote if You Deduct the Millions of People who Voted Illegally."” The Washington Post, November 27. $<$ https://www.washingtonpost.com/news/the-fix/wp/2016/11/27/donald-trump-i-won-thepopular-vote-if-you-deduct-the-millions-of-people-who-voted-illegally/>. 
Table 1. Trump Voter's Support for Resistance of Election Defeat (Binary Logit Model)

Dependent variable:

Support resistance

(1)

(2)

\section{Popular vote margin}

$-0.0056(0.0049)$

$-0.0072(0.0051)$

Age

(baseline: under 35)

35-49

$0.0240(0.0645)$

50-64

$-0.0614(0.0628)$

Over 65

$-0.1697^{* *}(0.0685)$

\section{Education}

(baseline: no college)

Some college

$-0.0537(0.0525)$

College degree

$0.0307(0.0770)$

\section{Household income}

(baseline: less than $\$ 25,000$ )

\$25,000-\$74,999

$0.0041(0.0525)$

$\$ 75,000-\$ 124,999$

$0.0165(0.0708)$

Over $\$ 125,000$

$0.0113(0.0914)$

\section{Party ID}

(baseline: not Republican)

Lean Republican

$-0.0029(0.0814)$

Republican

$0.0802(0.0751)$

Strong Republican

$0.0707(0.0642)$

Male

$-0.0552(0.0458)$

News interest

$0.0403(0.0289)$

Acknowledgement of racism

Constant

$-0.0245^{*}(0.0134)$

Observations

$0.4427^{* * *}(0.0447)$

$0.4304^{* * *}(0.1332)$

Log Likelihood

510

501

Akaike Inf. Crit.

$-380.3468$

$-363.8858$

Note: Table entries are binary logit coefficients with standard errors in parentheses. Dependent variable is coded 0 for "Trump should concede defeat and commit to a peaceful transfer of power" and 1 for "Trump should resist the results of the election through measures such as discrediting the results as invalid, declaring a state of emergency, and/or taking any means possible to remain in office." Self-reported news interest is coded as a continuous variable, where higher values indicate more engagement with news and media. Acknowledgement of racism is a continuous variable for the extent to which respondents agree that "White people in the U.S. have certain advantages because of the color of their skin, with higher values indicating more agreement. ${ }^{* * *}=$ Results significant at 0.01 level. ${ }^{* *}=$ Results are significant at 0.05 level. ${ }^{*}=$ Results are significant at 0.10 level. 
Table 2. Trump Voters' Reasons for Him to Resist Results of Potential Electoral College Loss

\begin{tabular}{lcc}
\hline \hline Statement & $\mathrm{n}$ & \% of Respondents \\
\hline Partisanship/Negative partisanship & $\mathbf{7 3}$ & $\mathbf{4 0 \%}$ \\
Support Trump & 64 & $35 \%$ \\
Democrats are radicals & 14 & $8 \%$ \\
Concerns regarding election legitimacy & $\mathbf{6 7}$ & $\mathbf{3 7 \%}$ \\
Election irregularities & 41 & $22 \%$ \\
Voter fraud/Mail-in-ballots & 31 & $17 \%$ \\
Other reasons & $\mathbf{6 5}$ & $\mathbf{3 6 \%}$ \\
Democrats are corrupt & 39 & $21 \%$ \\
Biden is incompetent & 11 & $6 \%$ \\
Other & 18 & $10 \%$ \\
\hline \hline
\end{tabular}

$n=183$

Note: Respondents could be coded under more than one category. 
Figure 1. Support for Trump Resisting the Results of a Biden Electoral College Victory Across Popular Vote Margins

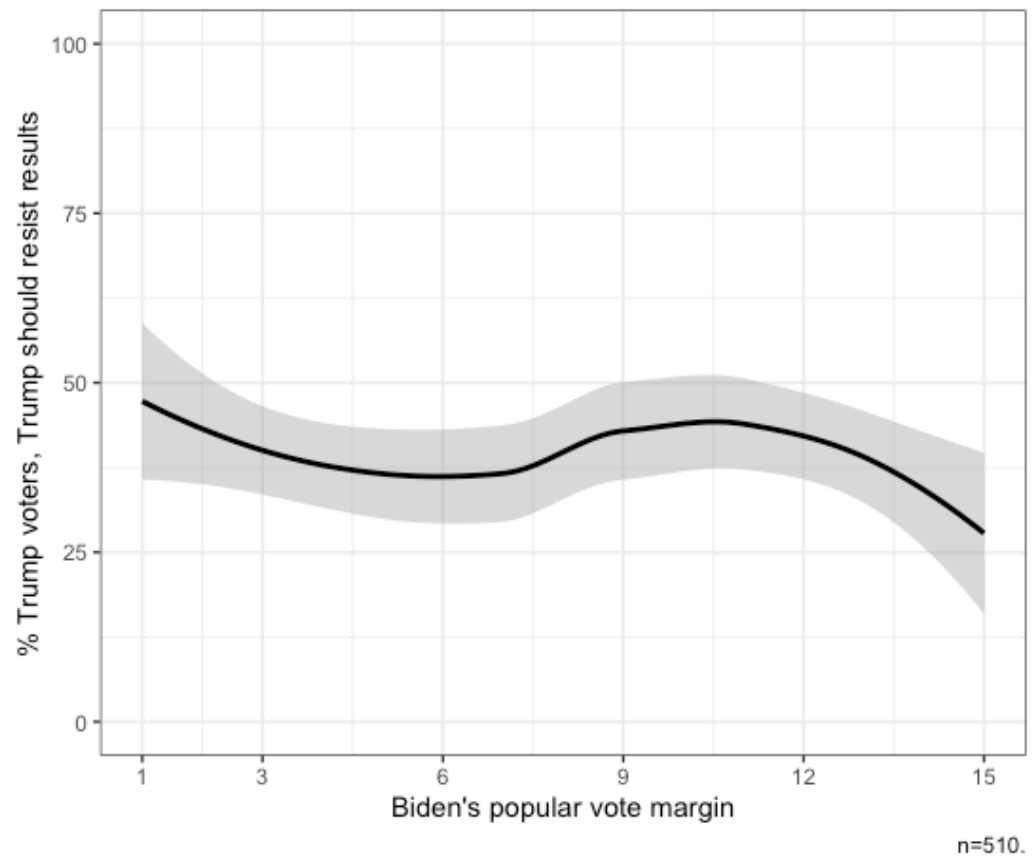

